Journal of

Literary Education

\title{
Types of word-image relationships appearing in Polish language textbooks
}

\section{Tipo de relaciones entre palabra e imagen que aparecen en los libros de texto de polaco}

\section{Tipus de relacions entre paraula i imatge que apareixen als llibres de text de polonés}

\author{
Justyna Bajda. University of Wrocław, Poland \\ (D) https://orcid.org/0000-0001-7402-090X
}

Dorota Michułka. University of Wrocław, Poland. dorota.michulka@uwr.edu.pl

(iD) https://orcid.org/0000-0002-7237-2618

How to cite this paper:

Bajda, Justyna \& Michułka, Dorota (2018). Types of word-image relationships appearing in Polish language textbooks. Journal of Literary Education, (1), 79-106.

https://doi.org/10.7203/JLE.1. 12361 